
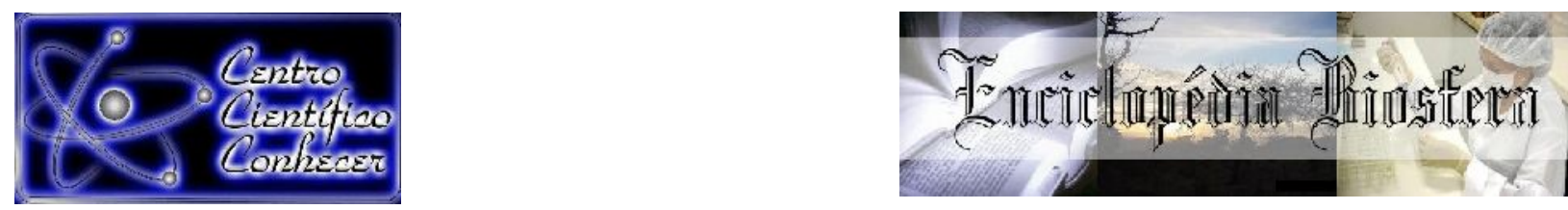

\title{
ENTRE MEMÓRIAS, NARRATIVAS E COSTURAS: AÇÕES INTERDISCIPLINARES DE EMPODERAMENTO FEMININO EM UMA COOPERATIVA DE COSTURA
}

\footnotetext{
Fabiana Jordão Martinez ${ }^{1}$, Rita Tatiana Cardoso Erbs², Juliana Pereira Araújo ${ }^{3}$, Maria Paulina de Assis ${ }^{4}$

1 Doutora em Ciências Sociais e mestra em Antropologia social pela UNICAMP. Professora adjunta da Unidade Acadêmica de História e Ciências Sociais da Universidade Federal de Goiás, Regional de Catalão.

(fabiana jordao@yahoo.com.br)

2 Graduada em psicologia - PUCRS, mestre em educação - PUCRS e doutora em educação - PUCRS, professora de Psicologia da Educação da Universidade Federal de Goiás, pesquisadora de Histórias de vida e narrativas (auto) biográficas

${ }^{3}$ Doutora em Educação, professora de Didatica da Universidade Federal de Goiás, Regional de Catalão.

Doutora em Educação: Currículo pela Pontifícia Universidade de São Paulo, pesquisadora em Design Thinking e Mobile Learning, professora de Psicologia da Educação da Universidade Federal de Goiás, campus de Catalão.

Recebido em: 06/04/2018 - Aprovado em: 10/06/2018 - Publicado em: 20/06/2018 DOI: 10.18677/EnciBio_2018A136
}

\begin{abstract}
RESUMO
Apesar da experiência do cooperativismo ser relativamente recente no Brasil, diversos trabalhos têm apontado sua importância para a melhoria da renda e da qualidade de vida de comunidades e grupos distintos em face de um cenário econômico e social marcado pela desigualdade e, sobretudo, pelas desigualdades de gênero. Embora as propostas de cunho coletivista e solidário sejam ainda estranhas ao modo de produção capitalista, estas produzem não só bens, mas principalmente, subjetividades. Enfocando uma cooperativa de costureiras na cidade de Catalão, GO e o seu respectivo procedimento de incubação através da INESSOL - Incubadora de Empreendimentos Sócio Solidários (vinculada a Universidade Federal de Goiás), neste trabalho serão analisados os dilemas e impasses presentes neste contexto, bem como os significados em jogo durante as reuniões no processo de diagnóstico pela incubadora. Estes encontros têm se constituído como espaços onde os sujeitos se constituem narrativamente, construindo e interpretando suas experiências, identidades e selves e também como um espaço de constituição da experiência. Uma categoria histórica construída através das singularidades individuais, mas principalmente através dos mecanismos hegemônicos em que a diferença e a subalternidade são construídas coletivamente (SCOTT,1999) dando emergência a categorias que atuam no direcionamento de uma nova forma de empoderamento feminino.
\end{abstract}

PALAVRAS-CHAVE: Cooperativismo, Empoderamento Feminino, Incubadora. 


\title{
BETWEEN MEMORIES, NARRATIVES AND SEAMS: INTERDISCIPLINARY ACTIONS OF FEMALE EMPOWERMENT IN A SEWING COOPERATIVE.
}

\begin{abstract}
Although the experience of cooperativism is relatively recent in Brazil, several studies have pointed out its importance for the improvement of income and the quality of life of communities and groups concerning economic and social scenarios where people suffer all kinds of inequality, above all, inequalities of genre. Although proposals of a collectivist and solidary nature are still away from the capitalist mode of production, they produce not only goods, but mainly subjectivities. Focusing on a cooperative of seamstresses in the city of Catalão, GO and its respective incubation procedure through INESSOL - Incubator of Social and Solidary Entrepreneurship (linked to the Federal University of Goiás), this paper analyzes the dilemmas and impasses present in this context, as well as the meanings at stake during the meetings in the diagnostic process by the incubator. These meetings with the cooperative have been constituted as spaces where subjects are narratively constituted, constructing and interpreting their experiences, identities and selves and also as a space of constitution of the experience. A historical category constructed through individual singularities, but mainly through the hegemonic mechanisms in which difference and subalternity are collectively constructed (SCOTT, 1999), giving rise to categories that act in the direction of a new form of feminine empowerment.
\end{abstract}

KEYWORDS: Cooperativism, Female Empowerment, Incubator.

\section{INTRODUÇÃO}

Embora não seja novidade, as experiências com Economia Solidária e cooperativismo serem relativamente recente no Brasil, diversos trabalhos têm apontado a importância para a melhoria da renda e da qualidade de vida de comunidades e grupos distintos em face de um cenário econômico e social marcado pela desigualdade e, sobretudo, pelas desigualdades de gênero. Apesar de remontar as décadas de 40 e 50, o cooperativismo no Brasil passa por dois marcos institucionais precisos, sendo o primeiro o sancionamento da lei no 5.764/1971, (que regulou e criou regras específicas para a criação de cooperativas) e o segundo a tentativa de unificar o cooperativismo no Brasil através da criação do sistema da Organização das Cooperativas Brasileiras (Sistema OCB), presente em cada estado do Brasil, e formado por três entidades que atuam em âmbitos diferentes, porém intrinsecamente relacionados ao desenvolvimento das cooperativas ${ }^{5}$ (MOTTA, 2015).

A economia solidária é definida por duas principais características: 1. igualdade de direitos, em que os meios de produção são de posse coletiva e 2. a autogestão, isto é, os empreendimentos de economia solidária são geridos pelos próprios trabalhadores coletivamente de forma, cada membro ganha de acordo com

\footnotetext{
${ }^{5}$ Seriam elas: a) a Organização das Cooperativas Brasileiras (OCB), que tem como pilar a representação Institucional e política; b) a Confederação Nacional das Cooperativas (CNCoop) , cujo objetivo é a representação sindical e, c) Serviço Nacional de Aprendizagem do Cooperativismo (Sescoop), cujo objetivo é promulgar a cultura cooperativista e o aperfeiçoamento da gestão de cooperativas. Dentro disso, o Sistema OCB divide o cooperativismo em 13 ramos de atividades que se pulverizam no total de 6800 cooperativas brasileiras, que congregam cerca de 11,5 milhões de associados, dos quais 338 mil ocupam postos de trabalho (MOTTA, 2015).
} 
a receita obtida pela venda do que produz ou sendo considerados pela coletividade como mais merecedores - seja pela maior experiência, habilidade ou qualificação podem ganhar mais pela hora trabalhada do que os que têm menos daquelas qualidades. Empreendimentos de economia solidária não estão submetidos a qualquer autoridade externa ou interna à coletividade; seus dirigentes (quando existem) são eleitos pelo conjunto dos sócios e devem cumprir a atividade de chefia em consonância às diretrizes aprovadas em assembleia de todos trabalhadores; cada membro do empreendimento tem direito a um voto em todas as decisões. Como consequência, vigora neste modelo a repartição coletiva do trabalho e das sobras líquidas para os associados (SINGER et al., 2014).

Neste panorama, embora também esteja inserido na tradição geral do país que encabeça o cooperativismo agropecuário (com cerca de 1600 cooperativas), o estado de Goiás possui cerca de 243 cooperativas que congrega 11 dos 13 ramos de atividades descritos pela OCB (MOTTA, 2015).

A emergência das mulheres na Economia Solidária e de forma mais ampla, nos movimentos sociais, rompeu com a invisibilidade como trabalhadora e proporcionou a eclosão como sujeitos políticos. É na década de 90 que as instituições começam a aderir aos recortes de gênero presentes nas desigualdades sociais. Trata-se de um momento em que o processo de revolução tecnológica que reorganiza a produção social por meio da reestruturação produtiva das economias nacionais e dos processos de acumulação flexível, extinguindo várias funções de trabalho, a precarização de ramos de atividade, a terceirização no processo produtivo e a diminuição média dos salários que ampliaram o desemprego e formaram um exército de reserva de trabalhadores e de comércio informal (ANTUNES, 2014).

Dentro disso, o cooperativismo aparece como uma via alternativa para pessoas excluídas do mundo do emprego, ainda que apresentem alta capacidade produtiva. No que tange às mulheres, de certo modo, sempre estiveram excluídas do sistema capitalista que historicamente não absorveu o potencial feminino e as delegaram à inferiorização social reiterando o status feminino como decorrente da sua capacidade de reprodução social, isto é, manter e gerir o ciclo de vida, o que inclui as tarefas de geração e cuidado, bem como o gerenciamento e manutenção do espaço doméstico (OLIVEIRA et al., 2015; HIRATA, 2016).

Se o capitalismo se constitui baseado na premissa de haver trabalhadores livres para venderem a força de trabalho, o custo da reprodução da força de trabalho têm sido pago pelas mulheres em suas famílias. Uma vasta produção da teoria feminista tem considerado as relações de poder dos homens sobre as mulheres na conceitualização da divisão sexual do trabalho; ela se expressa no princípio hierárquico de que o trabalho masculino tem sempre um valor superior ao trabalho feminino. Dentro deste princípio, a mesma função tem valores diferentes se é feita no espaço privado ou no público, se é destinada ao consumo próprio ou ao mercado, se é realizada por mulheres ou homens (KERGOAT, 2010; HIRATA, 2016).

Assim, não surpreende que esta assimetria cultural se reflita numericamente, e de forma bastante expressiva, em termos da permanência feminina no espaço doméstico, refletindo um quadro de desigualdade: sete em cada 10 homens na população economicamente ativa trabalham ou procuram emprego, e menos de cinco em cada 10 mulheres estão na mesma situação. A diferença de rendimentos é marcante: as mulheres recebem $73,8 \%$ dos rendimentos dos homens. As 
desigualdades refletidas nestes números é fruto de uma cultura patriarcal, que reproduz e hierarquiza uma divisão social do trabalho desigual (BRASIL, 2008).

Em 2010, as mulheres informaram que gastavam 25,9 horas por semana em atividades domésticas não remuneradas (IPEA, 2010), enquanto os homens declararam usar 10 horas nas mesmas tarefas (BRASIL, 2013-2015). De forma mais geral, as mulheres são $70 \%$ da população pobre do mundo e detém $1 \%$ da propriedade (ONU, 2009).

Atualmente as mulheres constituem maciçamente a grande maioria dos empreendimentos de economia solidária evidenciando o protagonismo político e empoderamento (FERRARINI et al., 2018). Diversos trabalhos têm apontado a troca de experiência de mulheres e a integração na estrutura de classes na sociedade capitalista como componentes fundamentais no empoderamento feminino e na participação política (SILIPRANDI, 2017).

Para Miriam Nobre (2003), esta incorporação se deu a partir do momento em que grupos de mulheres populares se empenharam em gerar renda para garantirem o funcionamento do próprio grupo e justificarem para si e sua família as tardes em que se ausentam de casa para estarem com as companheiras. Assim, a inserção das mulheres na economia solidária tem como ponto de partida a consciência da invisibilidade, da marginalização e do não reconhecimento do protagonismo das mulheres.

Se a experiência do cooperativismo é recente no Brasil, no âmbito das políticas sociais é também recente a perspectiva transversal que incorpora o recorte de gênero, bem como os esforços em ressignificar alguns conceitos chaves referentes a participação feminina na dinâmica social. Isso deve se traduzir em condições objetivas para o acesso ao mercado de trabalho, políticas de acesso a terra, a moradia, a água, formas de financiamento que atendam às mulheres em situação de vulnerabilidade social, direito a documentação, ao crédito e à assistência técnica, à comercialização da pequena produção familiar, entre outras medidas de forma articulada (BRASIL, 2013-2015) ${ }^{6}$.

A economia solidária se propõe a romper com a divisão social do trabalho através de várias outras rupturas: entre o proprietário dos meios de produção, entre trabalho intelectual e trabalho manual e da implementação e gestão democrática e práticas inovadoras de organização do trabalho. Mas se de um lado, esta divisão denota a inserção das mulheres na sociedade de classes, ela também o faz reproduzindo as mesmas associações culturais que hierarquizam gênero na cultura, como é o caso das tarefas de cuidado do lar e dos familiares no espaço doméstico, mais geralmente delegadas as mulheres (NOBRE, 2003).

Alguns estudos mostram que enquanto a identidade do homem trabalhador se associa ao trabalho assalariado formal (sendo sua passagem por cooperativas transitória), muitas mulheres ao optarem pela economia solidária, estão também

\footnotetext{
${ }^{6}$ Um dos grandes instrumentos que garante a mediação no diálogo entre governo e sociedade civil é - Plano Nacional de Políticas para as mulheres (PNPM), que reforça a participação social das mulheres no fortalecimento do Estado democrático como constitutiva de todas as fases de implementação e execução das políticas públicas. No caso do cooperativismo, este documento prevê como linha de ação, a "Promoção da autonomia econômica das mulheres por meio da assistência técnica e extensão rural, do acesso ao crédito e do apoio ao empreendedorismo, ao associativismo, ao cooperativismo e à comercialização, com fomento a práticas de economia solidária." (BRASIL, 2013-2015).
} 
"optando" por uma ocupação de tempo parcial e flexível e por trabalhos que facilitam a administração do tempo (NOBRE, 2003; FERRARINI, 2016). Isso possibilita maior disponibilidade para o cuidado de crianças, idosos e doentes, tarefa considerada "feminina" (KERGOAT, 2010).

Assim, ao mesmo tempo em que o efetivo de mulheres aumenta nos empreendimentos de economia solidária, este se constitui na grande maioria dos casos por mulheres chefes de família sem projetos de vida profissional, fragilizando as condições para ingresso no mercado de trabalho, especialmente pela via do emprego formal, que é a mais estimulada (FERRARINI, 2016). Assim, embora a Economia Solidária se apresente como uma via alternativa a inserção feminina na sociedade de classes, o modelo cooperativista tem suscitado diversas contradições na sua implementação.

No Brasil, o percurso da Economia Solidária se cruza com percurso das Incubadoras Tecnológicas de Cooperativas Populares (ITCPs), inicialmente inspiradas nas incubadoras de empresas tecnológicas, porém com a missão de incubar grupos de trabalhadores, cooperativas e empresas solidárias. No final dos anos 1990 e início dos anos 2000 surgiram várias organizações de apoio à formação de empreendimentos solidários, criadas por movimentos sociais, instituições religiosas, organizações de cooperativas etc (ESTEVES et al., 2017).

As incubadoras podem ter objetivos diferentes na forma de atuação e dentre os quatro tipos possíveis de incubadoras, identificam-se dois que serão importantes para este trabalho: 1. as incubadoras de universidades, que buscam transferir os resultados das pesquisas universitárias (desenvolvimento de novos produtos e tecnologias), com o objetivo de proporcionar aos alunos experiência em gestão de negócio e um papel contínuo na capacitação industrial, e; as incubadoras públicas, orientadas para a geração de emprego e desenvolvimento empresarial, juntamente com o desenvolvimento de produtos, a diversificação econômica e o estímulo ao empreendedorismo (FERREIRA, 2018).

Este trabalho teve como objetivo analisar contradições da experiência feminina no cooperativismo através do estudo de caso de uma cooperativa de costureiras no interior de Goiás, incubada pela INESSOL, (Incubadora de Empreendimentos Sócio Solidários da Universidade Federal de Goiás, Regional de Catalão), que encaixa-se com os dois tipos de incubadora descritos acima.

\section{MATERIAL E MÉTODOS}

A Coopermodas é uma cooperativa de costureiras situada em Catalão, sudoeste de Goiás, iniciada em 2013 e tinha como objetivo a produção de vestuário. Esta iniciou seus trabalhos com cerca de 13 cooperadas e era composta desde seu surgimento, com o acompanhamento e o processo de incubação pela INESSOL (Incubadora de Empreendimentos Sócio Solidários vinculada a Universidade Federal de Goiás). Esta, por sua vez, é uma Incubadora de Empreendimentos Sócio solidários ligada a UFG, sem fins lucrativos, possui uma perspectiva interdisciplinar agregando em seu quadro docentes e discentes de diversas áreas do conhecimento (Pedagogia, Psicologia, Engenharia de Produção, Antropologia, Biologia, Administração). Desde o início, a INESSOL procurou seguir a risca o método de incubação proposto por Cortegoso et al., (2005), entendido como referencial para produção de conhecimento, ensino e intervenção profissional relacionado à Economia Solidária. Fazem parte desta proposta de método de incubação questões 
referentes à capacitação dos participantes de grupos atendidos pela incubadora reafirmando, entre outros aspectos:

1. Relevância de formação destes indivíduos em diferentes dimensões (no mínimo para a Economia Solidária, para a gestão administrativa e para o trabalho técnico); 2. Compromisso da incubadora de criar condições para que esta formação ocorra: (a) de modo permanente, em todas as oportunidades de interação com estes indivíduos, (b) a partir de estratégias diversificadas, por meio de regras, mas também e, em algumas situações, principalmente, a partir de modelos, de conseqüências e de sinalizações facilitadoras de discriminações em relação a aspectos do ambiente e de seu próprio agir; 3. Perspectiva de autonomia do grupo e plena cidadania de seus membros; 4. Reciprocidade do processo educativo, entendendo que a interação é produtora de formação também para os formadores; 5. Reconhecimento da responsabilidade de gerar, específica, proposital e planejada, condições para aprendizagem dos participantes do processo (inclusive a sua própria), como parte fundamental do papel de educador. (CIA;CORTEGOSO , 2007)

Além da formação e desenvolvimento dos alunos como profissionais e pesquisadores, a INESSOL também busca: a- explorar novos espaços para prestar serviço à comunidade; b- integrar o trabalho científico ao trabalho comunitário, catender ao propósito das atividades de extensão e cultura da Universidade; dproduzir trabalhos científicos, como Trabalhos de Conclusão de Curso e artigos para publicação em periódicos acadêmicos apresentar resultados de pesquisa em eventos científicos.

A parceria da INESSOL com a Coopermodas foi firmada em 2013 através de projetos de extensão que previam a assessoria da incubadora no estabelecimento de convênios e parcerias, busca por editais e execução de projetos. Ao longo de três anos, esta parceria permitiu a aquisição de um rico maquinário, o material completo para a montagem de uma loja que fica no mesmo espaço da oficina (prateleiras, araras, balcões) e o aluguel do amplo espaço tutelado pela prefeitura do município.

Os dados desta pesquisa foram coletados através de pesquisa participante, método consagrado pela Antropologia, entre julho de 2016 e julho de 2017, período em que os membros e colabores da INESSOL participaram ativamente da dinâmica da cooperativa através de encontros semanais que ocorriam no espaço da cooperativa (que então situava-se no centro da cidade) presidido pela então presidente que pouco antes e de forma bastante vaga, procurou a INESSOL, solicitando ajuda para uma possível "reestruturação interna" da cooperativa.

O relato de experiência que consta neste trabalho foi fornecido através dos dados coletados durante estes encontros semanais, e integram desde um diário de campo a gravações de áudio coletadas com a permissão dos integrantes durante os encontros. Nestas ocasiões, as discussões eram feitas em roda de modo relativamente informal; todos falavam suas impressões dos acontecimentos, das demandas da cooperativa, expressavam suas aflições e angústias.

Por outro lado, o processo de identificação dos problemas e dificuldades enfrentados pelos sujeitos foi pautado pela metodologia da pesquisa ação. $O$ saber produzido pela pesquisa não é verticalizado entre os especialistas ou corpo docente e ou científico, mas deve ser horizontalizado e apropriado por todos os agentes que participaram do processo. Assim, este tipo de pesquisa enfatiza a socialização do saber, tentando romper com o monopólio do conhecimento, através da participação dos sujeitos na análise e solução de seus problemas. Esta metodologia também se aproxima muito do Design Thinking, um conjunto de técnicas, métodos e 
ferramentas que para além da indústria e da arte, tem se estendido para áreas sociais como a Educação Popular tendo como objetivo proporcionar a identificação de problemas e busca de soluções priorizando os desejos e vozes das comunidades e grupos sociais envolvidos e pesquisados ${ }^{7}$.

\section{RESULTADOS E DISCUSSÃO}

De forma geral, em julho de 2016, quando a INESSOL foi novamente procurada pelas cooperadas da Coopermodas, a primeira etapa do processo desta nova parceria, foi a identificação de problemas. A cooperativa existia desde 2013 e desde então já havia tido a assessoria da incubadora; contudo, adquiridos os recursos e os meios de trabalho, as cooperadas relatavam a necessidade de uma "reestruturação". As cooperadas alegavam um sentimento de desalento e desnorteio, sensação que teve como estopim um evento específico: o furto de parte do contingente de roupas da loja em uma noite, totalizando um montante de $R \$$ $60.000,00$ da produção total. Mas não era somente este fato que desencadeava a desmotivação pela qual as cooperadas passavam. Junto a isso, a sensação de desalento vinha acompanhada pela percepção de que já não era mais possível seguir no mesmo itinerário que então vinha sendo percorrido: as cooperadas haviam perdido o espírito coletivo, não se viam como proprietárias de seus meios de produção.

Embora as propostas de cunho coletivista e solidário sejam ainda estranhas ao modo de produção capitalista, elas produzem não só bens, mas principalmente, subjetividades e contradições que adquiriram contornos específicos no que configura neste estudo como estudo de caso. Um dos grandes problemas do cooperativismo está na dificuldade de criação de uma identidade de grupo baseada na cooperação. Parte desta identidade consiste em criar uma experiência trabalhadora em seus próprios termos, isto é, fora da hegemonia das relações capitalistas e mais respaldada por relações coletivistas e comunitárias.

Assim, existe toda uma literatura cujo propósito tem sido evidenciar que, embora o modelo de relações horizontais de trabalho, sejam a condição necessária das cooperativas, na prática, a tendência seja que os cooperados tomem como referência 0 modelo de relações empregatícias verticais (patrão-empregado), baseado no assalariamento, e em valores individualistas. Afinal é a necessidade de uma remuneração fixa mensal que os levam a ingressar em uma cooperativa de trabalho ou de produção.

Assim, as associadas da Coopermodas relataram a falta de união entre as costureiras, a competitividade (algumas procuravam "sair a frente" de outras quando apareciam algumas demandas de costura, visando o lucro todo para si) e a desarmonia nas relações internas. De todas as cooperadas, poucas eram as que costumavam estar assiduamente na cooperativa e dispostas a cumprir os prazos na execução de trabalhos de costura. Por isso, apesar do quadro de cooperadas estar formalmente constituído por 13 mulheres, havia uma rotatividade muito alta; a grande maioria ingressou na cooperativa apenas para aprender a costurar e ao aprenderem, saiam em busca de seus próprios caminhos.

Em função disto havia um permanente desequilíbrio operacional: os serviços eram prejudicados, pois quando a demanda era muito alta (seja em número de

\footnotetext{
${ }^{7}$ Oficina "Design Thinking na educação popular: abordagem para a extensão em áreas da economia solidária", ministrada pela profa. Dra. Maria Paulina de Assis para a INESSOL em 24/10/2016.
} 
peças a serem feitas ou em número de serviços), havia escassez de costureiras para cumprir os prazos; quando a demanda era muito baixa, não gerava lucros necessários sequer para cobrir os custos fixos da cooperativa.

De todo modo, este processo, bem como as narrativas das cooperadas, foram adquirindo consistência durante as reuniões semanais entre a incubadora e as cooperadas, visto que raramente apareciam mais de quatro mulheres nestas ocasiões. Na única ocasião em que quase todas as 13 cooperadas iniciais estiveram presentes, a diretora geral, submetida a grande pressão por parte das associadas, órgãos parceiros e conveniados, havia cogitado a venda dos equipamentos da cooperativa, bem como a dissolução da mesma, levando as cooperadas a acreditarem na possibilidade de terem alguma participação na cota final deste processo ${ }^{8}$. Nesta mesma ocasião, ocorreram muitos desentendimentos e ofensas pessoais entre as cooperadas, o que levou a decisão de traçar algumas estratégias fundamentais no processo de incubação como um todo.

Desde a mudança na coordenação da INESSOL em julho de 2016, que constituiu uma espécie de retomada do projeto da Coopermodas, até o momento, o enfoque recaiu na primeira etapa que consistiu na identificação de problemas através da observação, da escuta e do diálogo com as cooperadas, exercício fundamental no papel de incubação (FILHO et al., 2009). Mas este processo, já tem rendido alguns pontos positivos e possibilitado as condições de traçar estratégias para uma segunda etapa, que seria a criação e a tradução em estruturas de oportunidades, soluções e protótipos daquilo que foi coletado entre os usuários. A seguir a descrição desta primeira etapa:

Após um complexo processo de escutas, narrativas e reflexões, como primeiro resultado, a incubadora identificou uma falta de identidade geral no processo total de cooperativismo. Era cada vez mais nítida a sensação de desalento que pairava sobre a Coopermodas, estava menos relacionada a uma falta de formação no aprendizado, ou a instabilidade de uma demanda de serviços de costura que pudesse suprir continuamente a remuneração, lucros e dividendos das cooperadas do que a construção de uma identidade profissional.

A experiência coletiva da costura reúne múltiplas afecções e vivências inscritas nas trajetórias singulares de cada uma delas, passando pelos significados do que é uma cooperativa, e finalmente desembocando na ausência de um segmento de produtos, de um nicho de mercado, através do qual as cooperadas as cooperadas pudessem ancorar suas perspectivas mais concretas e finalmente, uma identidade.

A falta de continuidade dos serviços prestados é uma parte importante deste quadro geral e a instabilidade de renda é parte de uma experiência geral das cooperativas, como bem demonstram outros casos. Para Bueno (2001), a necessidade de uma renda estável "faz com que surjam muitas pró-cooperativas e

\footnotetext{
${ }^{8}$ Este evento ilustra o completo desconhecimento das cooperadas quanto às leis e burocracias que regem a dinâmica cooperativista. A dissolução de uma cooperativa não é um processo simples. Apesar "da cooperativa" não ser propriedade privada, não podendo ser vendida e nem comprada, as quotas partes são. Estas, não podem ser comercializadas a terceiros, mas apenas aos cooperados. A lei ainda põe um limite em que um cooperado pode ter no máximo $1 / 3$ das quotas partes da cooperativa. Segundo a Lei das Cooperativas, se uma cooperativa se dissolver o liquidante deve "realizar o ativo social para saldar o passivo e reembolsar os associados de suas quotas-partes, destinando o remanescente, inclusive o dos fundos indivisíveis, ao Banco Nacional de Crédito Cooperativo S/A." (Art. 68, Inc. VI da Lei das Cooperativas.). Fonte: http://www.educativa.com.br/acooperativa/
} 
poucas cooperativas de fato: unidas, legalizadas e produtivas.". No caso da Coopermodas, tudo parecia indicar que parte dos problemas era mais a consequência de uma dinâmica que foi implementada ao inverso, primeiro através de moldes mais pragmáticos (com a aquisição de um local de funcionamento e de maquinário), e não através da questão fundamental que congrega todo empreendimento: o produto a ser produzido e como produzi-lo.

Até o momento, as cooperadas haviam trabalhado de forma esporádica com uma infinidade de produtos: lingeries, roupas de moda, uniformes, bordados, roupas de cama, sacolas e embalagens. Em meio ao desalento, diversas decisões errôneas (na perspectiva das cooperadas) haviam sido tomadas, como a compra de estoques de roupas em Goiânia e que estavam sendo vendidas na cooperativa a preços bastante altos para cobrir os custos ${ }^{9}$.

Assim, os encontros entre incubadora e cooperadas eram espaços não só de troca de experiências, escutas e reflexões, mas principalmente, de epifanias onde as cooperadas organizavam as suas experiências em uma experiência coletiva, a saber, a experiência da constituição da Coopermodas, buscando os significados de todo o processo, do que era e do que poderia ser a cooperativa. Assim, grande parte do problema identificado pela incubadora como uma "falta de identidade" havia sido identificado antes pelas próprias mulheres cooperadas, que já haviam juntando seus saberes e vivências visitando outras cooperativas de costura (como a Cooperoca da Rocinha, no RJ), e concluíam que grande parte do investimento deveria ser em uma frente de trabalho e nas reais possibilidades desta se concretizar.

Havia o desejo amplo de se firmarem em um segmento de mercado específico na região, em que a médio e a longo prazo pudesse ser concretizado em uma marca que identificasse a Coopermodas como um espaço por excelência. Mas junto a este desejo, haviam também necessidades imediatas a serem sanadas, junto a certeza de um capital fixo. Assim, parte do trabalho de incubação tem sido feito em torno de duas questões fundamentais: a) as possibilidades de angariar e manter cooperadas mesmo com todas intempéries b) $\mathrm{O}$ tipo de serviço e produto a oferecer. Em relação a este último item, há que se considerar que: a) Haviam poucas cooperadas empenhadas em continuar, logo, b) não podiam atender grandes demandas de serviços e quantidades de peças e c) também não dispunham de um capital inicial para refazerem oferecendo mais serviços e ou tipos de produtos.

A segunda etapa consistiu na busca por componentes que pudessem proporcionar segurança e identidade entre elas. Como resultado, foi gerado um modelo de negócios construído junto às cooperadas durante algumas das atividades propostas durante as reuniões. Esta atividade consistiu na montagem de um quadro de modelo de negócios que permitiu às cooperadas desenvolver e esboçar modelos de negócio novos ou existentes. Havia a dúvida se fariam uniformes para empresas, lingeries, varejo de roupas ou varejo e atacado de enxovais de cama e mesa; ou ainda, se ofereceriam cursos de formação. Na medida em que a conversa fluía, as ideias iam surgindo, empolgando e estimulando as pessoas a abraçarem a cooperativa. Como resultado parcial, obteve-se o modelo de negócios elencado no quadro 1.

\footnotetext{
${ }^{9}$ É evidente que em se tratando de uma cooperativa de costureiras, onde o principal negócio é a confecção, a compra de roupas é uma alternativa contraproducente e inviável.
} 
QUADRO 1- Quadro de modelos de negócios obtido em reunião com as cooperadas da Coopermodas.

\begin{tabular}{ccl}
\hline Segmento de mercado & $\bullet$ & Cama/mesa/banho (longo prazo) \\
& $\bullet \quad$ Uniformes (curto prazo) \\
& $\bullet \quad$ Serviços - cursos (curto prazo) \\
\hline Clientes & Escolas, empresas, prefeituras, comércios e hotéis. \\
\hline Canais & Facebook, site, mala direta, telefone, whatsapp. \\
\hline Atividades principais & $\bullet$ & Atendimento ao cliente \\
(cargos e tarefas) & $\bullet$ & Gestão financeira \\
& $\bullet$ & Gestão interna. \\
& & Custos : fornecedores, concorrentes \\
& $\bullet$ & Receitas: encomendas, mensalidades, projetos \\
& & patrocínios. \\
& & \\
\hline Custos. & Pessoas, máquinas, escritório, loja, utensílios de cozinha, \\
& prateleiras, capacitação.
\end{tabular}

Evidentemente estes resultados são ainda provisórios. As próximas etapas consistem em reavaliar este modelo através de uma pesquisa de mercado in loco que considere variáveis como: as necessidades da região, cotação de possíveis fornecedores e compradores. E para além da questão do modelo de negócios, a INESSOL produzirá resultados através da atuação em outras frentes de trabalho junto as cooperadas da Coopermodas, tais como: 1. a questão da inclusão digital das cooperadas para execução de planilhas e divulgação on line de seus produtos; 2. A reelaboração do regimento interno da cooperativa e de sua estrutura organizacional; 3. A busca por estratégias de amealhamento de mais cooperadas dispostas a abraçar o empreendimento; 4. Entrevistas e grupos focais com as cooperadas a fim de compreender as demandas individuais e buscar estratégias de dinâmicas de trabalho que priorizem o coletivo e as relações verticais; 5 . Oficinas e dinâmicas em grupo que tematizem a questão da economia solidária, do cooperativismo e do empoderamento feminino.

Os dois últimos itens são de extrema importância, pois remetem as trocas, reciprocidades e ao jogo de buscas e desejos dos sujeitos envolvidos. A compreensão das singularidades das trajetórias individuais das cooperadas, bem como a dedicação sobre um trabalho intensivo a respeito dos significados envolvidos no cooperativismo e na economia solidária certamente fez com que estes encontros dialógicos se estabeleçam como um espaço de constituição da experiência.

Para Joan Scott (1999), a experiência deve ser compreendida como categoria histórica que se constrói duplamente, não só através dos relatos individuais dos sujeitos, mas também através dos mecanismos hegemônicos e repressores em que a diferença e a subalternidade são construídas; a saber, na relação entre os níveis: estrutural e "psicológico", coletivo e particular. Assim, estes encontros tem sido e continuarão a ser analisados como espaços em que os sujeitos se constituem narrativamente, construindo e interpretando suas experiências, identidades e selves, mas principalmente, como um espaço onde estes repertórios de narrativas e memórias são integrados em diversos níveis estruturais, permitindo a emergência de conceitos e categorias que atuam no direcionamento das ações e principalmente, de uma nova forma de empoderamento feminino. 


\section{CONCLUSÃO}

O objetivo deste trabalho era demonstrar através de um estudo de caso de uma cooperativa urbana de costureiras no interior de Goiás, algumas das contradições presentes nos empreendimentos de economia solidária constituídos por mulheres.

A principal delas é a dificuldade das mulheres cooperadas da Coopermodas em se enxergar como sujeitos políticos e sociais em um processo que demanda autonomia na tomada de decisões sobre a dinâmica do trabalho (tempo, recorrência, processos) e sobre o conhecimento das regras de mercado (financiamento, crédito, engrenagem mercantil). Dentro disso, reside a própria dificuldade destes sujeitos em construírem-se como uma classe trabalhadora através de uma identidade. A impossibilidade de consolidar uma identidade profissional em torno de uma dinâmica de trabalho sinérgica das cooperadas reside também na falta de uma experiência coletiva em torno do empreendimento solidário, pois na visão dos sujeitos, o caráter sui generis da cooperativa reside no fato deste ser visto como "fora" da perspectiva hegemônica capitalista. Assim, a cooperativa não é vista como uma profissão ou trabalho, mas uma atividade a qual se dedicar "quando sobra algum tempo", "se sobrar". Para que isso sofra alguma mudança, seria preciso a incorporação da perspectiva de que as cooperadas são proprietárias e produtoras em seu próprio negócio; e principalmente (e talvez disso sejam decorrentes as dificuldades apontadas acima) a construção de uma visão de sistema produtivo alternativa à perspectiva hegemônica do capitalismo, a saber, a desnaturalização da técnica e da organização de trabalho capitalista como sinônimo de eficiência. Na ausência de um espaço de incorporação de uma visão ao mesmo tempo coletiva e mais tecnicista e estrategista, são gerados desentendimentos, competitividade e desarmonia.

Dentro disso, mais que "transmitir conhecimentos", a INESSOL está ali para trocar saberes, desenvolver junto às cooperadas uma narrativa comum na construção desta experiência coletiva, encontrando "o caminho do meio", no espaço entre a técnica e a racionalidade do capital e a humanização e subjetivação das relações.

\section{REFERÊNCIAS}

ANTUNES, R. Desenhando a nova morfologia do trabalho no Brasil. Estudos Avançados, v. 28, no 81, 2014. Disponivel em: http://www.scielo.br/pdf/ea/v28n81/v28n81a04.pdf.

http://dx.doi.org/10.1590/S0103-40142014000200004

BRASIL. Secretaria de Políticas para Mulheres. Plano Nacional de Políticas para Mulheres 2013-2015. Disponível em:http://www.spm.gov.br/assuntos/pnpm/publicacoes/pnpm-2013-2015-em22ago13.pdf acesso 29/04/2018.

BRASIL. Secretaria de Políticas para Mulheres. Plano Nacional de Políticas para Mulheres 2008. Disponível em: http://portal.mec.gov.br/dmdocuments/planonacional_politicamulheres.pdf

BUENO, P. F.Z. Gênero e cooperativismo: a participação das mulheres nas cooperativas de trabalho. Trabalho de Final de Curso. IFCH/ UFRGS, 2001. Link: http://www.lume.ufrgs.br/handle/10183/88263 
CORTEGOSO, A. L.; SHIMBO, I.; ZANIN, M.; FONTES, D. A.; FONTES, N.; JESUS, V. M. B. de; UEHARA, M. S.; MASCIO, C. C.; COSTA, A. A. V. da; NARDINI, T. Método de Incubação como Referencial para Atendimento a Empreendimentos Solidários: a Experiência da Incubadora Regional de Cooperativas Populares da UFSCar. Trabalho apresentado na $2^{\text {a Jornada }}$ Universitaria sobre Cooperativismo, Economía Solidaria y Procesos Asociativos, Montevidéo, Uruguai, 2005

CIA, F., CORTEGOSO, A.L. Condutas de mediadores em processos de decisão coletiva como condição para uma educação emancipatória na Economia Solidária, Revista Psicologia e Sociedade v.19 n.2 Porto Alegre May/Aug. 2007. Disponivel em: http://www.scielo.br/scielo.php?script=sci_arttext\&pid=S0102$71822007000200014 \& \operatorname{lng}=$ en\&nrm=iso\&tlng=pt

ESTEVES, E.G., DA SILVA, A.C.G., MAGALHÃES, R. A efetividade das práticas de apoio dirigidas a empreendimentos solidários. Anais $6^{\circ}$ Congresso Iberoamericano de Investigação Qualitativa, 2017.

FERRANTE, V.L. S B. DUVAL, H.C, BERGAMASCO, S.M.P.P. BOLFE, A.P.F. Na trajetória dos assentamentos rurais: mulheres, organização e diversificação. In: NEVES, D. P.; DE MEDEIROS,L.S. (Org.). Mulheres camponesas: trabalho produtivo e engajamentos políticos. Núcleo Bandeirante: Qualidade Gráfica e Editora, 2013. Disponível em: https://wp.ufpel.edu.br/leaa/files/2013/06/mulheres_camponesas_11.pdf.ISBN 97885-63749-07-9 ISBN 978-85-63749-07-9.

FERRARINI, A.V. Inclusão produtiva na política de assistência social: workfare à brasileira ou ampliação de direitos? Anais do $40^{\circ}$ Encontro da ANPOCS, Caxambu, SP, 2016. Disponivel em: http://www.anpocs.com/index.php/papers-40encontro/st-10/st24-5/10388-inclusao-produtiva-na-politica-de-assistencia-socialworkfare-a-brasileira-ou-ampliacao-de-direitos/file

FERRARINI, A.V.GAIGER, L.I.,SCHIOCHET,V. O estado da arte e a agenda de pesquisa em economia solidária no Brasil, Revista Brasileira de Sociologia, V.6, no $12,2018$.

FERREIRA, F.M. Economia Solidária: Um Estudo sobre as Incubadoras Públicas Municipais. Dissertação defendida no Programa de Pós-Graduação em Administração Pública. Faculdade de Ciências e Tecnologia, UFG, 2018. Link: https://repositorio.bc.ufg.br/tede/bitstream/tede/8510/5/Disserta\%C3\%A7\%C3\%A3o \%20-\%20Fernanda\%20Machado\%20Ferreira\%20-\%202018.pdf

FILHO, G.C.F; DA CUNHA,E.V. Incubação de Redes Locais de Economia Solidária: lições e aprendizados a partir da experiência do projeto Eco-Luzia e da metodologia da ITES/UFBA. Revista O\&S, Salvador, v.16, n.51, p. 725-747 - Outubro/Dezembro, 2009 
HIRATA, H. Mulheres brasileiras: relações de classe, de "raça" e de gênero no mundo do trabalho, Confins Revista Franco-Brasileira de Geografia, no 26, 2016. Link : https://journals.openedition.org/confins/10754.

KERGOAT, D. Dinâmica e consubstancialidade das relações sociais. Revista Novos Estudos no 86, março de 2010. Disponível em: http://www.scielo.br/pdf/nec/n86/n86a05.pdf

IPEA. Mulher e trabalho: avanços e continuidades. Comunicados do Ipea no 40, março de 2010.

MOTTA, F.N. Agenda Institucional do Cooperativismo. Brasília, Sistema OCB, 2015. Link: http://www.goiascooperativo.coop.br/arquivos/downloads/agendainstitucional-do-cooperativismo-2015-1-11129914.pdf .

NOBRE, M. Mulheres na economia solidária. In CATTANI, A. A Outra economia. Editora Veraz e Unitrabalho: Porto Alegre, 2003.

OLIVEIRA, M.D.L.S;KALSING, V.S.S.;OLIVEIRA, R.A.; OLIVEIRA, B.A.M; PEREIRA, V. D.S. Mulheres, relações de gênero e divisão sexualdo trabalho em Minas Gerais: negras, assentadas de reforma agrária e da economia solidária em Lavras, Guapé e Prados. Revista Retratos de Assentamento, v.18, n1, 2015. Disponível em:

http://www.retratosdeassentamentos.com/index.php/retratos/article/view/179/164

ONU: Relatório da ONU. A Armadilha do Gênero: Mulheres, violência e Pobreza, 70\%. Anistia Internacional, 2009.

SCOTT, J.W. Experiência in LEITE DA SILVA, Alcione et al (orgs.). Falas de gênero. Santa Catarina: Ed Mulheres, 1999. ISBN 9788586501166

SILIPRANDI,E. Rompendo a Inércia Institucional: As Mulheres Rurais e a Política Nacional de Agroecologia e Produção Orgânica. In. SAMBUICHI, R.H.R.. DE MOURA, I.F.; DE MATTOS,LM.; DE AVILA,M.L, SPINOLA, P.A.C; DA SILVA, A.P.M. A política nacional de agroecologia e produção orgânica no Brasil : uma trajetória de luta pelo desenvolvimento rural sustentável. Brasília: Ipea, 2017. ISBN: 978-85-60548-99-6. Disponível em:

http://www.ipea.gov.br/portal/images/stories/PDFs/livros/livros/144174_politicanacional_WEB.PDF

SINGER,P; DA SILVA, R.M.A.; SCHIOCHET,V. Economia solidária e os desafios da superação da pobreza extrema no plano Brasil sem miséria In CAMPELLO, T.; FALCÃO, T. DA COSTA, P.V. O Brasil sem miséria. Brasília: MDS, 2014. 